\title{
Impact of the COVID-19 pandemic on testing services for HIV, viral hepatitis and sexually transmitted infections in the WHO European Region, March to August 2020
}

Daniel Simões ${ }^{1,2}$, Annemarie Rinder Stengaard ${ }^{3}$, Lauren Combs ${ }^{3}$, Dorthe Raben ${ }^{3}$, The EuroTEST COVID-19 impact assessment consortium of partners 4

1. EPIUnit-Instituto de Saúde Pública, Universidade do Porto, Porto, Portugal

2. Grupo de Ativistas em Tratamentos (GAT), Lisboa, Portugal

3. Centre of Excellence for Health, Immunity and Infections (CHIP), Rigshospitalet, University of Copenhagen, Copenhagen, Denmark.

4. The members of the EuroTEST consortium of partners are listed at the end of the article

Correspondence: Annemarie Rinder Stengaard (annemarie.rinder.stengaard@regionh.dk)

Investigators:

The EuroTEST COVID-19 impact assessment consortium of partners: Anastasia Pharris, Andrew Winter, Ann K Sullivan, Ann-Isabelle von Lingen, Antons

Mozalevskis, Cary James, Casper Rokx, Cristina Agusti, Daria Alexeeva, Elena Vovc, Erika Duffell, Giorgi Kuchukhidze, Jordi Casabona, Jürgen K Rockstroh, Justyna D Kowalska, Kristi Rüütel, Lara Tavoschi, Laura Fernandez-Lopez, Magnus Unemo, Maria Buti, Michael Krone, Nicole Seguy, Otilia Mardh, Soudeh Ehsani, Teymur Noori, Valerie Delpech

Citation style for this article:

Simões Daniel, Stengaard Annemarie Rinder, Combs Lauren, Raben Dorthe, The EuroTEST COVID-19 impact assessment consortium of partners. Impact of the COVID-19 pandemic on testing services for HIV, viral hepatitis and sexually transmitted infections in the WHO European Region, March to August 2020 . Euro Surveill. 2020;25(47): pii=2001943. https://doi.org/10.2807/1560-7917.ES.2020.25.47.2001943

We present preliminary results of a coronavirus disease (COVID-19) impact assessment on testing for HIV, viral hepatitis and sexually transmitted infections in the WHO European Region. We analyse 98 responses from secondary care $(n=36)$, community testing sites $(n=52)$ and national level $(n=10)$. Compared to pre-COVID-19, $95 \%$ of respondents report decreased testing volumes during March-May and $58 \%$ during June-August 2020. Reasons for decreases and mitigation measures were analysed.

The coronavirus disease (COVID-19) continues to challenge healthcare systems across the World Health Organization (WHO) European Region [1-4]. As World AIDS Day 2020 approaches, it serves as a reminder about the importance to maintain a strong HIV response at all levels. Further, as framed in the Sustainable Development Goals (SDGs) [5] and recent European and global guidance [6-8], it is critical to approach testing for HIV, hepatitis B (HBV), hepatitis C (HCV), and sexually transmitted infections (STIs), namely chlamydia, syphilis and gonorrhoea, in an integrated and synergistic manner.

Challenges for HIV, hepatitis B, hepatitis C and sexually transmitted infections control Early diagnosis and linkage to care for these infections are key challenges in the WHO European Region, where an estimated one in five people living with HIV do not know their infection status [9], and half are diagnosed at a late stage [9-12]. In the European Union/European Economic Area (EU/EEA), only an estimated $20.3 \%$ (2.4$71.8 \%)$ of persons with HBV and $26.8 \%(4.1-96.8 \%)$ of those with HCV are aware of their infection $[13,14]$.

The COVID-19 pandemic has required rapid adaptation of health systems and public health measures, at a scale never previously witnessed. Here we report preliminary results of an online survey assessing the impact of COVID-19 on testing for HIV, HBV, HCV and STIs in the 53 countries of the WHO European Region.

The survey (Supplementary Table S1) was developed by a consortium of partners [15] and distributed through the consortium member's respective networks between 14 October and 13 November 2020 to a wide range of actors involved in the provision of testing services in the WHO European Region (laboratories, primary care units, secondary level care clinics, community sites and national level public health institutions or ministries of health). Key questions comprised the quantitative impact on testing volume (asked in broad categories of percentage decrease/increase), main reasons for the observed impact, measures put in place to mitigate it and areas where guidance or support were needed. 
Changes in testing volume for HIV, HBV, HCV and STIs a by infection and category of change in (A) March-May 2020 and (B) June-August, compared with March-May 2019 in 34 WHO European Region countries ( $\mathrm{n}=98$ respondents)

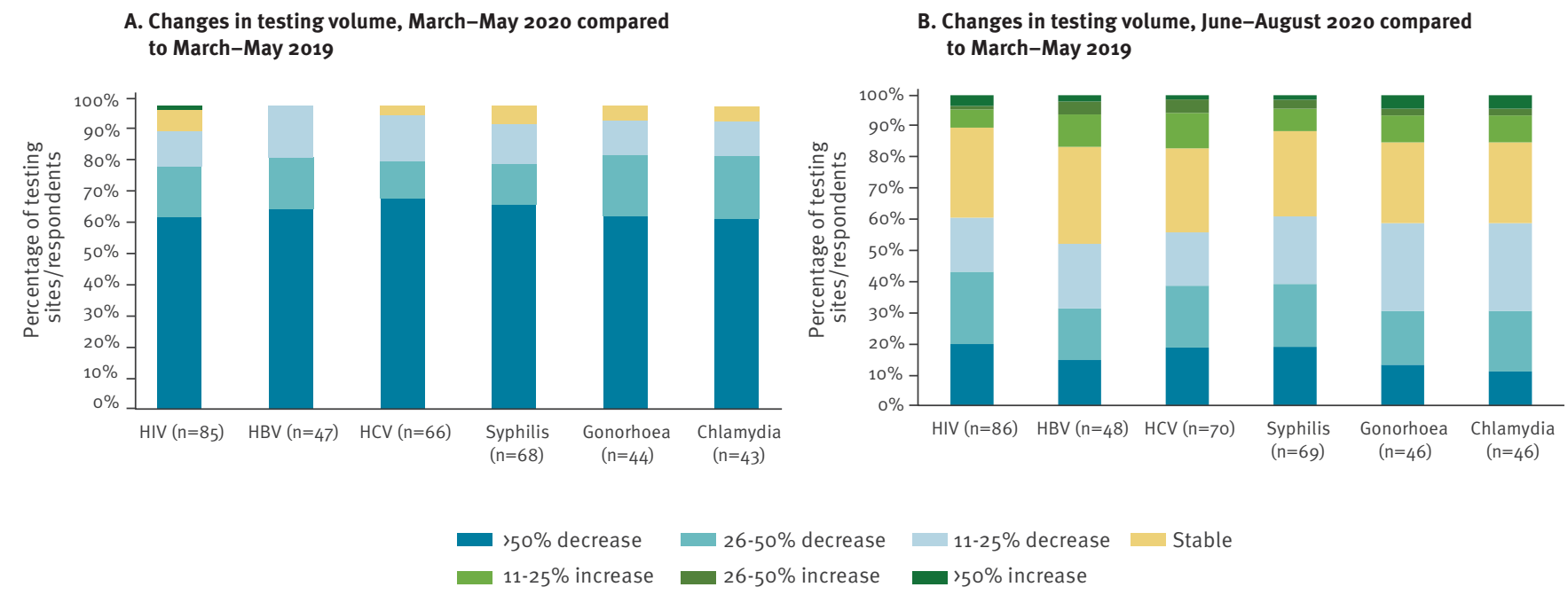

HBV: hepatitis B virus; HCV: hepatitis C virus; STI: sexually transmitted infections; WHO: World Health Organization.

${ }^{a}$ Chlamydia, syphilis and gonorrhoea.

\section{Magnitude of decline in testing}

A total of 98 survey responses, received as at 10 November 2020, were included in this preliminary analysis. They include 52 community and non-governmental organisations (CBOs and NGOs) providing testing for at least one of these infections, 36 secondary level/specialist healthcare (SHC) providers, and 10 national level public health institutes or ministries of health (NLPHM) from 34 countries in the WHO European Region (23 EU/ EEA and 11 non-EU/EEA) (Supplementary Table S2). Survey responses from laboratories $(n=5)$ and primary healthcare facilities $(n=5)$ were not included in this analysis, because of the low numbers of respondents.

Across infections, almost all (95\%; 92/98) respondents reported testing decreases from March to May 2020 as compared with the same period in 2019 , including $64 \%(63 / 98)$ who reported severe disruptions to testing provision (> $50 \%$ decline in testing volume) (Figure 1). Between June and August 2020, 58\% (57/98) still reported testing volume decreases, however, the degree of disruption was less severe with 20\% (20/98) reporting $>50 \%$ declines in testing and $14 \%$ (14/98) even reporting increases in testing volume (Figure 1 ).

These findings were consistent across all infections surveyed, with between nine of 86 HIV testing providers and eight of $48 \mathrm{HBV}$ testing providers reporting increases in testing volume from June to August 2020 (Figure 1).

Although not directly comparable, severe disruption in testing services ( $\geq 50 \%$ decrease) were reported by all settings for the period March to May 2020 compared with March to May 2019 (Figure 2). Assessing the average change across all infections, $41 / 52$ of community-based testing sites and 19/36 of secondary level care sites reported severe testing disruptions. For the period June-August 2020 (compared with the same pre-COVID baseline), fewer sites reported severe disruptions: $12 / 52$ of community sites and 4/36 of secondary level sites. National level data (based on 10 responses) suggested $a>50 \%$ decrease in five countries in the early period and smaller decreases in the later period (Figure 2).

Reported estimations of positivity tended to decrease or remain stable during March to May 2020 and remained stable or increased slightly from June to August, in comparison with a March 2019 baseline (data not shown).

Reasons for the observed decreases in testing volume (Table 1) included (in order of frequency reported): testing site closure during lockdown, reduced staff, reduced attendance and fewer appointments scheduled, fewer serological samples drawn, laboratories overburdened and fewer referrals to the facility.

\section{Measures to mitigate decline in testing}

Respondents reported a range of new measures implemented to mitigate the impact on testing. Remote appointments were overall the most frequently reported (25/36 of SHC and 35/52 of CBO and NGO sites). Both settings also introduced stricter criteria for test offer (13/36 SHC sites and 16/52 CBO and NGO), appointment-only testing (13/36 SHC sites, 25/52 CBO and NGO) and referral to other testing sites $(6 / 36 \%$ SHC, 19/52 CBO and NGO). 
Changes in testing volume for HIV, HBV, HCV and STIs ${ }^{a}$, by setting and category of change in (A) March-May 2020 and (B) June-August 2020, compared with March-May 2019, in 34 WHO European Region countries ( $\mathrm{n}=98$ respondents)

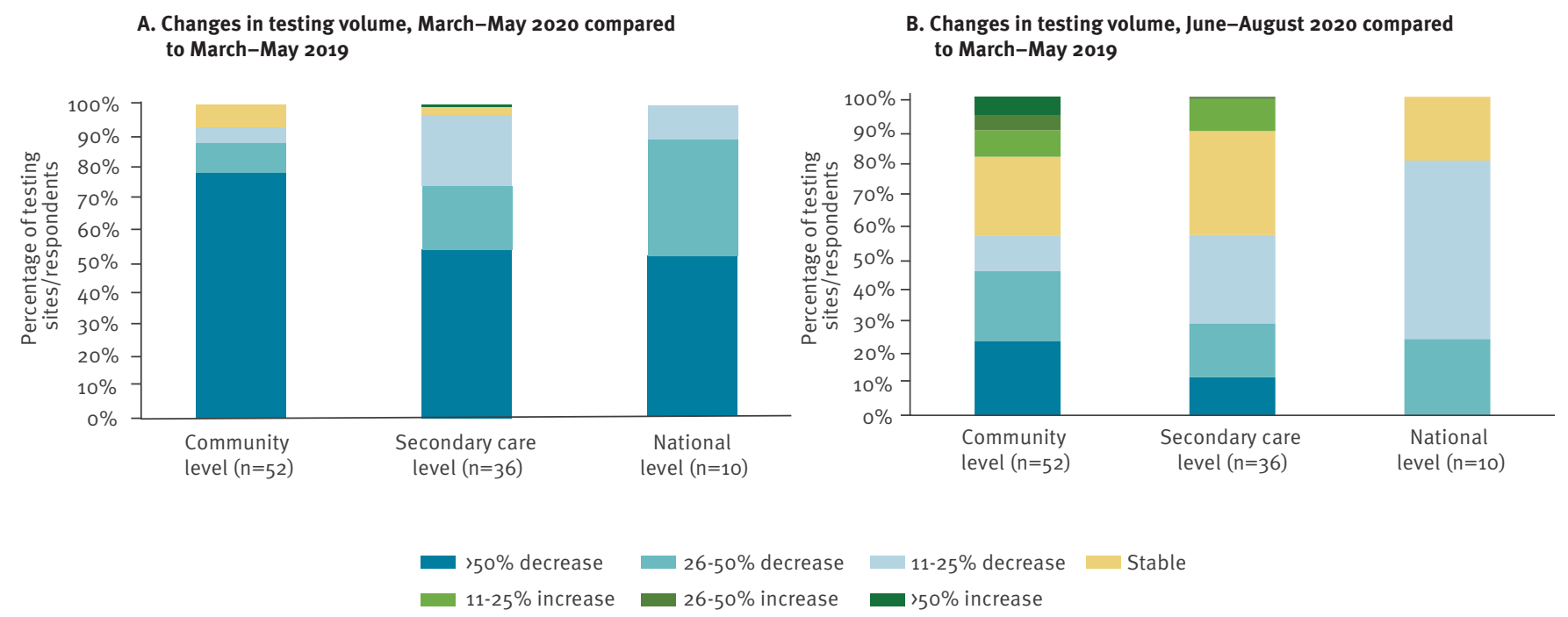

HBV: hepatitis B virus; HCV: hepatitis C virus; STIs: sexually transmitted infections; WHO: World Health Organization.

${ }^{a}$ Chlamydia, syphilis and gonorrhoea.

In SHC sites, other new measures included staff reinforcements (8/36) and home-based sampling (6/36). In CBOs and NGOs, self-testing (23/52), testing campaigns (19/52) funding reallocations (13/52) and expanded outreach $(22 / 52)$ were reported.

At the national level, regarding changes in testing modalities available, home-based sampling (2/10), HIV self-testing (1/10) and lay provider testing (1/10) were reported (Table 1 ).

\section{Needs for guidance or support}

Regarding guidance or support needs (Table 2), the most frequently reported ones were additional human resources ( $16 / 36$ for SHC and 23/52 for CBO and NGO), and increased financial support (35/52 of CBO and $\mathrm{NGO} ; 13 / 36$ of SHC). One third (16/52) of CBO and NGO listed regulatory changes as important. Regulatory issues mentioned were regulation of self-testing and community based/lay provider testing, as well as adapted guidance for $\mathrm{CBO}$ and NGO to continue to provide services during lockdown, removing or revising prohibitive legislations or regulations associated with specific practices or key populations (such as abortion, sex work or drug use). At the national level, four respondents stated that no particular support was needed while two mentioned programmatic guidance as important.

\section{Discussion and conclusions}

The COVID-19 pandemic has had considerable impact on testing for HIV, viral hepatitis and STIs in the WHO European Region. Our preliminary results show that
$95 \%$ of respondents from 34 countries reported testing less than half the expected number of people during the first months of the COVID-19 pandemic between March and May 2020. This continued, although to a lesser degree, between June and August 2020, when measures were less strict in most countries. These findings are indicating an important decline in testing volumes; however, it should be kept in mind that they represent broad categories of reported change and are based on best estimates rather than accurate data for some respondents.

For chronic infections such as HIV and viral hepatitis, delayed diagnosis and treatment may result in further long-term consequences including sequelae for individual patients $[16,17]$, and even a stalling of progresses achieved so far in controlling these infections in the WHO European Region.

Given the high reported impact on testing in community services, also documented in other reports [18-20], where efforts focus on key populations, our findings suggest that these vulnerable populations may have experienced further reduced access to testing and other essential services than before the pandemic.

With reported cases of COVID-19 being on the rise in the Region in the autumn of $2020[1,2]$ and movement restrictions being re-imposed in many countries $[21,22]$, support and guidance are paramount to minimise testing interruptions and ensure the long term sustainability of existing HIV, hepatitis and STIs testing services. Guidance should include contingency 


\section{TABLE 1}

Reported reasons ${ }^{\mathrm{a}}$ for observed declines in testing volumes for HIV, HBV, HCV and STIs ${ }^{\mathrm{b}}$ and measures implemented to restore testing provision ${ }^{c}$, by setting, in 34 WHO European Region countries, March-August 2020 ( $\mathrm{n}=98$ respondents)

\begin{tabular}{|c|c|c|c|}
\hline & $\begin{array}{l}\text { Community level sites } \\
\qquad(\mathrm{n}=52)\end{array}$ & $\begin{array}{l}\text { Secondary level care } \\
\text { sites }(n=36)\end{array}$ & National level $(n=10)$ \\
\hline & $\mathrm{n}$ & $\mathrm{n}$ & $\mathrm{n}$ \\
\hline \multicolumn{4}{|l|}{ Reasons for observed declines in testing volume } \\
\hline Testing site(s) closed during lockdown & 36 & 21 & 6 \\
\hline Staff re-allocated to support COVID-19 response & 8 & 15 & 5 \\
\hline Reduced staff in testing site & 31 & 11 & NA \\
\hline Fewer appointments scheduled/reduced attendance & 36 & 28 & 8 \\
\hline $\begin{array}{l}\text { Fewer serological samples drawn and sent to the laboratory/ } \\
\text { fewer referrals to blood draw/testing }\end{array}$ & 10 & 24 & NA \\
\hline No 'drop-in' service (only testing by appointment) & 26 & 15 & NA \\
\hline Fewer referrals to site & 13 & 18 & NA \\
\hline Changes in financing system & 10 & 4 & 0 \\
\hline Stock-out of test kits, tubes, reagents or consumables & 3 & 5 & 1 \\
\hline Triaging of patients ${ }^{d}$ & 16 & 12 & 2 \\
\hline Moved to telemedicine/remote consultations & 20 & 14 & NA \\
\hline Laboratories overburdened & NA & NA & 4 \\
\hline Other & 2 & 3 & 0 \\
\hline \multicolumn{4}{|l|}{ Measures implemented to restore testing provision } \\
\hline Remote counselling appointments & 35 & 25 & 0 \\
\hline Home-based sampling & 8 & 6 & 2 \\
\hline HIV self-testing (on-site or by referral) & 23 & 4 & 1 \\
\hline Triaging of patients ${ }^{d}$ & 16 & 13 & 0 \\
\hline No 'drop-in' service (only testing by appointment) & 25 & 13 & NA \\
\hline Referral to other testing sites & 19 & 6 & NA \\
\hline Staff reinforcement & 5 & 8 & 0 \\
\hline Funding reallocations & 13 & 1 & NA \\
\hline Expanded outreach testing & 11 & 4 & NA \\
\hline Testing campaigns & 19 & 4 & NA \\
\hline Revised diagnosis algorithm & NA & NA & 0 \\
\hline Community based testing & NA & NA & 0 \\
\hline Lay provider testing & NA & NA & 1 \\
\hline
\end{tabular}

COVID-19: coronavirus disease; HBV: hepatitis B virus; HCV: hepatitis C virus; NA: not asked to this group; STIs: sexually transmitted infections; WHO: World Health Organization.

${ }^{\text {a }}$ For each reported reason, respondents were asked to indicate if they perceived the impact level as major, medium or minor, responses here include major and medium.

${ }^{b}$ Chlamydia, syphilis and gonorrhoea.

${ }^{c}$ Each respondent could indicate more than one reason or new measure, hence the totals per column are higher than the number of respondents.

d Stricter criteria for who is being offered testing. 
Guidance or support considered important to reduce the impact of COVID-19 on testing for HIV, HBV, HCV and STIs ${ }^{a}$, by setting, in 34 WHO European Region countries, March-August 2020 ( $\mathrm{n}=98$ respondents)

\begin{tabular}{|c|c|c|c|}
\hline & $\begin{array}{l}\text { Community level sites } \\
\qquad(\mathrm{n}=52)\end{array}$ & $\begin{array}{l}\text { Secondary level care sites } \\
\qquad(n=36)\end{array}$ & $\begin{array}{l}\text { National level } \\
\qquad(n=10)\end{array}$ \\
\hline Additional human resources & 23 & 16 & 1 \\
\hline Increased financial support & 35 & 13 & 1 \\
\hline Regulatory changes & 16 & 2 & 0 \\
\hline Programmatic guidance & 4 & 1 & 2 \\
\hline Technical guidance & 6 & 3 & 1 \\
\hline Technical support on specific issue & 5 & 4 & 1 \\
\hline Procurement/supply chain related support & 6 & 4 & 1 \\
\hline Other & 4 & 2 & 0 \\
\hline None & 7 & 5 & 4 \\
\hline
\end{tabular}

COVID-19: coronavirus disease; HBV hepatitis B virus; HCV hepatitis C virus; STIs: sexually transmitted infections; WHO: World Health Organization.

a Chlamydia, syphilis and gonorrhoea.

planning and development of COVID-secure testing services in all settings.

The survey respondents report several new measures implemented because of the pandemic. Although these do not reflect an effort to recover testing operations, they aim to provide minimum services or adapt testing capacity. Complementary testing modalities for existing testing strategies such as self-testing (for HIV) and self-sampling (for HIV, hepatitis and STIs), had not been widely implemented before the pandemic [12]. They constitute important options to diversify and optimise access to testing that should be regulated and made available as part of policy and practice at a national level.

The EU/EEA and other Regional partners can play an instrumental role in accelerating stakeholder involvement, regulatory development and integration processes, including fostering cross-border cooperation and supporting exchange and implementation of best practices, as done through several European projects focusing on HIV, viral hepatitis and STI and bringing together different actors [6,23-26].

The COVID-19 response in several countries of the WHO European Region has shown capacity in rapidly responding to health threats, which has translated into the rapid scale-up of COVID-19 testing [27], new/ innovative initiatives to improve contact tracing for this infection [28] and implementation of adapted HIV, viral hepatitis and STI testing and linkage to care solutions $[29,30]$. This has shown that it is possible to mobilise resources and adapt policies in a short time, despite limited scientific evidence. These learnings can be transferred to the response planning of HIV and other infectious diseases, for which there is a larger evidence base and agreed SDGs.
As the COVID-19 pandemic - and future emerging infectious diseases - will likely remain a priority in the Region, it is important to ensure that the response to other infectious diseases is not compromised. Investing in integrated testing responses through dialogue of those involved at all levels, including for HIV, viral hepatitis and STIs, can speed up recovery of testing provision in the Region, particularly in the case of key populations, which often are at a higher risk of acquiring more than one infectious disease.

The EuroTEST COVID-19 impact assessment consortium of partners

Anastasia Pharris, ECDC, Stockholm, Sweden; Andrew Winter, International Union against Sexually Transmitted Infections (IUSTI) Europe, Glasgow, United Kingdom; Ann K Sullivan, Chelsea and Westminster Hospital NHS Foundation Trust, London, United Kingdom; Ann-Isabelle von Lingen, European AIDS Treatment Group (EATG), Brussels, Belgium; Antons Mozalevskis, WHO Regional Office for Europe, Copenhagen, Denmark; Cary James, World Hepatitis Alliance (WHA), London, United Kingdom; Casper Rokx, Erasmus University Medical Center, Rotterdam, the Netherlands; Cristina Agusti, Centre d'Estudis Epidemiològics sobre les ITS i Sida de Catalunya (CEEISCAT) - Centro de Investigación Biomédica en Red de Epidemiologia y Salud Pública (CIBERESP), Barcelona, Spain; Daria Alexeeva, AFEW International, Amsterdam, the Netherlands; Elena Vovc, WHO Regional Office for Europe, Copenhagen, Denmark; Erika Duffell, ECDC, Stockholm, Sweden; Giorgi Kuchukhidze, WHO Regional Office for Europe, Copenhagen, Denmark; Jordi Casabona, Centre for Epidemiological Studies on Sexually Transmitted Infections and HIV/AIDS of Catalonia (CEEISCAT), Catalan Health Department, Centros de Investigación Biomédica en Red Epidemiología y Salud Pública (CIBERESP), Barcelona, Spain; Jürgen K Rockstroh, Department of Medicine I, Univeristy Hospital Bonn, Bonn, Germany; Justyna D Kowalska, Medical University of Warsaw, Warsaw, Poland; Kristi Rüütel, National Institute for Health Development, Tallinn, Estonia; Lara Tavoschi, University of Pisa, Pisa, Italy; Laura Fernandez-Lopez, Centre for Epidemiological Studies on Sexually Transmitted Infections and HIV/AIDS of Catalonia (CEEISCAT), Catalan Health Department, Centros de Investigación Biomédica en Red Epidemiología y Salud 
Pública (CIBERESP), Barcelona, Spain; Magnus Unemo, WHO Collaborating Centre for STIs, Örebro University, Örebro, Sweden; Maria Buti, European Association for the Study of the Liver (EASL), Barcelona, Spain; Michael Krone, Aids Action Europe (AAE), Berlin, Germany; Nicole Seguy, WHO Regional Office for Europe, Copenhagen, Denmark; Otilia Mardh, ECDC, Stockholm, Sweden; Soudeh Ehsani, WHO Regional Office for Europe, Copenhagen, Denmark; Teymur Noori, ECDC, Stockholm, Sweden; Valerie Delpech, Public Health England, London, United Kingdom.

\section{Acknowledgements}

Funding statement: Daniel Simões is the recipient of PhD Grant PD/BD/128008/2016 from Fundação para a Ciência e Tecnologia (FCT).

\section{Conflict of interest}

None declared.

\section{Authors' contributions}

The EuroTEST COVID-19 impact assessment consortium of partners contributed to the development of the setting specific sections of the survey, helped disseminate the survey in their network and provided comments on the manuscript. All co-authors developed the manuscript focus and structure. DS led the data analysis and wrote the first draft of the manuscript, supported by AS and LC. All authors revised and validated the manuscript.

\section{References}

1. World Health Organization (WHO). WHO Coronavirus Disease (COVID-19) Dashboard. Geneva: WHO. [Accessed: 10 Nov 2020]. Available from: https://covid19. who.int/?gclid=CjwKCAiAL9BRBQEiwA-bm5fnMSWJRDXLxVTBghcKEiZ_L_4IdPntjALc94X 5PSVxnSGn1DSh_FhBoCmz4QAvD_BwE

2. European Centre for Disease Prevention and Control (ECDC). Increased transmission of COVID-19 in the EU/EEA and the UK - thirteenth update. Stockholm: ECDC;23 Oct 2020. Available from: https://www.ecdc.europa.eu/sites/default/files/ documents/RRA-COVID-19-EU-EEA-UK-thirteenth-update-23Oct-2020.pdf

3. Joint United Nations Programme on HIV/AIDS (UNAIDS). COVID-19 impacting HIV testing in most countries. Geneva: UNAIDS; 13 Oct 2020. Available from: https://www.unaids. org/en/resources/presscentre/featurestories/2020/ october/20201013_covid19-impacting-hiv-testing-in-mostcountries

4. World Health Organization Regional Office for Europe (WHO/ Europe). Statement - COVID-19: taking stock and moving forward together. Copenhagen: WHO/Europe; 29 Oct 2020. Available from: https://www.euro.who.int/en/health-topics/ health-emergencies/coronavirus-covid-19/statements/ statement-covid-19-taking-stock-and-moving-forward-together

5. World Health Organization (WHO). Progress report on HIV, viral hepatitis and sexually transmitted infections 2019. Accountability for the global health sector strategies, 20162021. Geneva: WHO; Jul 2019. Available from: https://www. who.int/hiv/strategy2016-2021/progress-report-2019/en/

6. European Centre for Disease Prevention and Control (ECDC). Public health guidance on HIV, hepatitis $B$ and $C$ testing in the EU/EEA - An integrated approach. Stockholm: ECDC; Nov 2018. Available from: https://www.ecdc.europa.eu/sites/default/ files/documents/hiv-hep-testing-guidance_o.pdf

7. European Centre for Disease Prevention and Control (ECDC), European Monitoring Centre for Drugs and Drug Addiction (EMCDDA). Public health guidance on prevention and control of blood-borne viruses in prison settings. Stockholm: ECDC and EMCDDA; Jul 2018. Available from: https://www.ecdc.europa. eu/sites/default/files/documents/Guidance-on-BBV-in-prisons. pdf

8. World Health Organization (WHO). Consolidated guidelines on HIV testing services. Geneva: WHO; Jul
2015. Available from: https://apps.who.int/iris/bitstream/ handle/10665/179870/9789241508926_eng.pdf?sequence $=1$

9. European Centre for Disease Prevention and Control (ECDC), WHO Regional Office for Europe. (WHO/

Europe). HIV/AIDS surveillance in Europe 2020 - 2019 data. Copenhagen: WHO/Europe; 2020. Available from: https://www.euro.who.int/en/publications/abstracts/ hivaids-surveillance-in-europe-2020-2019-data

10. World Health Organization Regional Office for Europe (WHO/Europe). Progress report on implementation of the Action Plan for the Health Sector Response to HIV in the WHO European Region. Copenhagen: WHO/Europe Europe; 5 Aug 2019. Available from: https://www.euro.who. int/__data/assets/pdf_file/0011/409097/69wdo8e_A_ ProgressReportHealth $\bar{S}$ ectorResponseToHIV_190397.pdf

11. Brown AE, Hayes R, Noori T, Azad Y, Amato-Gauci AJ, Pharris A, et al. , The Ecdc Dublin Declaration Monitoring Network. HIV in Europe and Central Asia: progress in 2018 towards meeting the UNAIDS 90-90-90 targets. Euro Surveill. 2018;23(48). https:// doi.org/10.2807/1560-7917.ES.2018.23.48.1800622 PMID: 30621820

12. European Centre for Disease Prevention and Control (ECDC). Continuum of HIV care. Monitoring implementation of the Dublin Declaration on partnership to fight HIV/AIDS in Europe and Central Asia: 2018 progress report. Stockholm: ECDC; 2019. Available from: https://www.ecdc.europa.eu/sites/ default/files/documents/HIV-continuum-of-care-monitoringdublin-declaration-progress-report-2018.pdf

13. World Health Organization (WHO). Global Hepatitis Report 2017. Geneva: WHO; 2017. Available from: https://apps.who. int/iris/bitstream/handle/10665/255016/9789241565455-eng. pdf;jsessionid=7450CA7E16C41F89D599FD74436CDA6F?sequ ence $=1$

14. European Centre for Disease Prevention and Control (ECDC). Monitoring the responses to hepatitis $B$ and $C$ epidemics in EU/ EEA Member States, 2019. Stockholm: ECDC; 2020. Available from: https://www.ecdc.europa.eu/sites/default/files/ documents/hepatitis-B-C-monitoring-responses-hepatitis-B-Cepidemics-EU-EEA-Member-States-2019.pdf

15. EuroTEST. Survey assessment of the impact of COVID-19 on testing for HIV, viral hepatitis and sexually transmitted infections in the WHO European Region. Copenhagen: EuroTEST. [Accessed 13 Nov 2020]. Available from: http://www.eurotest.org/Projects-Collaborations/ COVID-19-impact-assessment-on-testing

16. Mocroft A, Lundgren JD, Sabin ML, Monforte A, Brockmeyer N, Casabona J, et al. , Collaboration of Observational HIV Epidemiological Research Europe (COHERE) study in EuroCoord. Risk factors and outcomes for late presentation for HIVpositive persons in Europe: results from the Collaboration of Observational HIV Epidemiological Research Europe Study (COHERE). PLoS Med. 2013;10(9):e1001510. https://doi. org/10.1371/journal.pmed.1001510 PMID: 24137103

17. Lazarus JV, Picchio C, Dillon JF, Rockstroh JK, Weis N, Buti M. Too many people with viral hepatitis are diagnosed late - with dire consequences. Nat Rev Gastroenterol Hepatol. 2019;16(8):451-2. https://doi.org/10.1038/s41575-019-0177-Z PMID: 31320742

18. European Monitoring Centre for Drugs and Drug Addiction (EMCDDA). EMCDDA trendspotter briefing: Impact of COVID-19 on drug services and help-seeking in Europe. Lisbon: EMCDDA; 2020. Available from: https://www.emcdda.europa.eu/system/ files/publications/13073/EMCDDA-Trendspotter-Covid-19_ Wave-1-2.pdf

19. AFEW International. The impact of COVID-19 on civil society organisations in Eastern Europe and Central Asia: Results of a regional survey. Amsterdam: AFEW International; 2020. Available from: http://afew.org/wp-content/uploads/2020/10/ COVID-impact-survey-report-AFEW-International-2.pdf

20. European AIDS Treatment Group (EATG). EATG Rapid Assessment. COVID-19 crisis' Impact on PLHIV and on Communities most affected by HIV. Brussels: EATG; 2020. Available from: https://www.politico.eu/wp-content/ uploads/2020/04/EATG-Rapid-Assessment-COVID19-1-.pdf

21. European Observatory on Health Systems and Policies, World Health Organization Regional Office for Europe, European Commission. COVID-19 Health Systems Response Monitor. Copenhagen: European Observatory on Health Systems and Policies. [Accessed: 13 Nov 2020]. Available from: https:// www.covid19healthsystem.org/mainpage.aspx

22. European Centre for Disease Prevention and Control (ECDC). Data on country response measures to COVID-19. Stockholm: ECDC. [Accessed 12 Nov 2020]. Available from: https://www.ecdc.europa.eu/en/publications-data/ download-data-response-measures-covid-19

23. COBATEST Network. COBATEST. Badalona: COBATEST. [Accessed: 12 Nov 2020]. Available from: https://cobatest.org/ 
24. INTEGRATE Joint Action. INTEGRATE Joint Action. Copenhagen: Centre of Excellence for Health, Immunity and Infections. [Accessed: 12 Nov 2020]. Available from: https://integrateja. $\mathrm{eu} /$

25. EURO HIV EDAT. EURO HIV EDAT. [Accessed: 12 Nov 2020]. Available from: https://www.eurohivedat.eu/

26. Optimising testing and linkage to care for HIV across Europe (OptTEST). Optimising testing and linkage to care for HIV across Europe. [Accessed: 12 Nov 2020]. Available from: https://www.opttest.eu/

27. European Centre for Disease Prevention and Control (ECDC). Data on testing for COVID-19 by week and country. Stockholm ECDC. [Accessed: 25 Nov 2020]. Available from: https://www. ecdc.europa.eu/en/publications-data/covid-19-testing

28. MIT Technology Review. MIT Technology Review.

[Accessed: 25 Nov 2020]. Available from: https:/

www.technologyreview.com/2020/05/07/1000961/ launching-mittr-covid-tracing-tracker/

29. EUROTest. Spring European Testing Week, 15-22 May 2020: Results from the 2020 SETW. Copenhagen: EUROTest. 2020. Available from: http://www.testingweek.eu/ckfinder/userfiles/ files $/ 2020 /$ Evaluation $/ 2020 \% 20$ SETW_evaluation\%2oreport Final.pdf

30. European Testing Week. The EuroTEST initiative. [Accessed: 25 Nov 2020]. Available from: http://www.testingweek.eu/ get-involved/Webinars

\section{License, supplementary material and copyright}

This is an open-access article distributed under the terms of the Creative Commons Attribution (CC BY 4.0) Licence. You may share and adapt the material, but must give appropriate credit to the source, provide a link to the licence and indicate if changes were made.

Any supplementary material referenced in the article can be found in the online version.

This article is copyright of the authors or their affiliated institutions, 2020. 